\title{
Trocas gasosas em gravioleira 'Morada' sob adubação orgânica e mineral
}

\author{
Gaseous exchanges in soursop 'Morada' under organic and mineral fertilization
}

\author{
Altamiro Oliveira de Malta 1 \\ Msc. em Agronomia, Universidade Federal da Paraíba, Centro de Ciências Agrárias, Campus II \\ E-mail: altamiro1@ig.com.br \\ Walter Esfrain Pereira 2
Prof. Dr. do Departamento de Ciências Fundamentais e Sociais, Universidade Federal da Paraíba, Centro de
Ciências Agrárias, Campus II
E-mail: walterufpb@yahoo.com.br
}

Mariana Neves Nóbrega Torres 3

Graduada em Agronomia, Universidade Federal da Paraíba, Centro de Ciências Agrárias, Campus II

E-mail: marianannobrega@gmail.com

Alan Oliveira de Malta 4

Graduando em Agronomia, Universidade Federal da Paraíba, Centro de Ciências Agrárias, Campus II

E-mail: alan-oliveira@live.com

Diego Almeida Medeiros 5

Msc. em Agronomia, Universidade Federal da Paraíba, Centro de Ciências Agrárias, Campus II

E-mail: diegoa083@gmail.com

Jefferson Alves Dias 6

Msc. em Agronomia, Universidade Federal da Paraíba, Centro de Ciências Agrárias, Campus II

E-mail: jefferson_cz@hotmail.com

Resumo: Trabalhos envolvendo o efeito da adubação orgânica e química sob as trocas gasosas na gravioleira ainda são restritos na literatura científica. Assim, o objetivo deste experimento foi avaliar as trocas gasosas em gravioleira 'Morada' sob adubação orgânica e mineral. Foi instalado um experimento em um pomar de gravioleira com 42 meses de idade entre os meses de janeiro a setembro de 2014. O solo foi classificado como Latossolo Amarelo Distrófico. O delineamento experimental foi em blocos casualizados, com sete tratamentos e quatro repetições, com duas plantas por parcela. Os tratamentos utilizados foram: $\mathrm{T}_{1}=$ testemunha (sem adubação); $\mathrm{T}_{2}=$ adubação mineral $(\mathrm{NPK}) ; \mathrm{T}_{3}=$ esterco de bovino; $\mathrm{T}_{4}=$ esterco de aves; $\mathrm{T}_{5}=$ adubação mineral + esterco de caprino; $\mathrm{T}_{6}=$ esterco de aves $+3 \mathrm{~kg}$ de pó de rocha; $\mathrm{T}_{7}=$ esterco de caprino. As variáveis analisadas foram: concentração interna de $\mathrm{CO}_{2}$, condutância estomática, taxa de transpiração, taxa fotossintética, eficiência de carboxilação e do uso da água. As avaliações foram feitas em campo, após 60 dias da última adubação nitrogenada, no período das 8 às 11 horas. Os dados foram submetidos à análise de variância e ao teste de Tukey. A adubação mineral com NPK proporcionou maior taxa fotossintética e eficiência de carboxilação na gravioleira 'Morada'. A concentração interna de $\mathrm{CO}_{2}$, condutância estomática, taxa de transpiração e eficiência de uso da água não foram afetadas pelos tratamentos.

Palavras-chave: Annona muricata L.; Transpiração; Concentração de $\mathrm{CO}_{2}$. 


\begin{abstract}
Works involving the effect of organic and chemical fertilization under the gaseous exchanges in soursop are still restricted in the scientific literature. Thus, the objective of this experiment was to evaluate the gas exchange in soursop 'Morada' under organic and mineral fertilization. An experiment was installed in a 42-month-old soursop orchard from January to September 2014. The soil was classified as Yellow Latosol Distrophic. The experimental design was in randomized blocks, with seven treatments and four replications, with two plants per plot. The treatments used were: $\mathrm{T} 1=$ control (without fertilization); $\mathrm{T} 2=$ mineral fertilization $(\mathrm{NPK})$; $\mathrm{T} 3=$ bovine manure; $\mathrm{T} 4=$ poultry manure; $\mathrm{T} 5=$ mineral fertilization + goat manure; $\mathrm{T} 6=$ poultry manure $+3 \mathrm{~kg}$ of rock dust; $\mathrm{T} 7=$ goat manure. The variables analyzed were: internal $\mathrm{CO}_{2}$ concentration, stomatal conductance, transpiration rate, photosynthetic rate, carboxylation efficiency and water use. The evaluations were made in the field, after 60 days of the last nitrogen fertilization, in the period of 8 to 11 hours. Data were submitted to analysis of variance and Tukey test. Mineral fertilization with NPK provided higher photosynthetic rate and carboxylation efficiency in soursop 'Morada'. The internal $\mathrm{CO}_{2}$ concentration, stomatal conductance, transpiration rate and water use efficiency were not affected by treatments.
\end{abstract}

Keywords: Annona muricata L.; Transpiration; $\mathrm{CO}_{2}$ concentration.

\title{
1 Introdução
}

A fruticultura tornou-se nos últimos anos um dos mais promissores setores de investimento da agricultura, tal fato deve-se as ótimas condições edafoclimáticas existentes no País, bem como aos esforços do governo, iniciativa privada e aos avanços tecnológicos, favorecendo o desenvolvimento do setor (LIMA, 2012).

De acordo com Viana et al. (2013) apesar da disponibilidade de informações referenciando o uso de fontes orgânicas e mineral no crescimento e na produtividade das frutíferas, artigos envolvendo os efeitos da adubação orgânica e química nas trocas gasosas ainda são restritos.

Segundo Pompeu et al. (2010) e Lopes et al. (2011) o estudo das trocas gasosas nas culturas, por meio de características como: taxa de transpiração da folha, taxa de fotossíntese foliar, concentração de dióxido de carbono na folha, condutância estomática, permitem uma avaliação conjunta dos processos fisiológicos que estão ocorrendo no vegetal em resposta a fatores do meio e ao manejo.

De acordo com Ciompi et al. (1996) o nitrogênio pode afetar profundamente as trocas gasosas e as relações hídricas das plantas. Como regra, as taxas de fotossíntese decrescem com a redução dos teores foliares de $\mathrm{N}$; por outro lado, as respostas dos estômatos à deficiência de $\mathrm{N}$ é variável, ocorrendo desde incrementos a decréscimos na condutância estomática $(g s)$. Em muitas espécies, altas taxas de trocas gasosas estão associadas a altas concentrações de nitrogênio foliar (ALMEIDA, 2001). 
Para Qiu e Israel (1994) a disponibilidade de fósforo influencia o processo de fixação fotossintética do $\mathrm{CO}_{2}$ e altera o crescimento e o desenvolvimento das plantas. $\mathrm{O}$ decréscimo da atividade fotossintética, sob deficiência de fósforo, tem sido associado com o decréscimo na atividade da Rubisco e regeneração da Ribulose 1,5 bisfosfato (RAO e TERRY, 1995). Decréscimos de $\mathrm{P}$ entre o citoplasma e o estroma, gerados por redução da absorção de $\mathrm{P}$ no solo (SANTOS et al., 2006), podem levar a diminuições no consumo e na produção de ATP e NADPH (SHUBHRA et al., 2004), decréscimo na expressão de genes relacionados à fotossíntese, fechamento estomático e menor condutância do mesofilo.

O potássio atua como um osmorregulador dissolvido no suco celular, quando acumulado, cria um gradiente osmótico que permite o movimento de água, regulando a abertura e o fechamento dos estômatos, exercendo papel essencial na economia de água e turgescência das células, no transporte de carboidratos e na respiração (SHIMAZAKI, 2007; MELO JÚNIOR, 2014).

A utilização de adubos orgânicos de origem animal ou vegetal torna-se uma prática, útil e econômica para os pequenos e médios produtores, podendo contribuir para a melhoria da fertilidade e conservação do solo, maior aproveitamento dos recursos existentes na propriedade, como também na manutenção da umidade do solo (MARÇAL, 2011).

Diante do exposto, objetivou-se com esse estudo avaliar em experimento de campo as trocas gasosas da gravioleira 'Morada' sob adubação orgânica e mineral.

\section{Metodologia}

O experimento foi conduzido em pomar de gravioleiras da cultivar 'Morada', pertencente à Fazenda Quaty III, distrito de Santa Maria, localizado no município de Areia, PB. O referido município encontra-se inserido na mesorregião do Agreste paraibano e microrregião do Brejo paraibano, com as coordenadas geográficas de $6^{\circ} 57^{\prime} 42^{\prime \prime} \mathrm{S}$ e $35^{\circ} 41^{\prime}$ 43" W, a $618 \mathrm{~m}$ de altitude (GONDIM, 1999). O solo da área experimental é classificado como Latossolo Amarelo Distrófico. A vegetação nativa é de floresta subperenifólia e o relevo é fortemente ondulado (BRASIL, 1972).

O delineamento experimental foi em blocos casualizados, com sete tratamentos e quatro repetições, com duas plantas por parcela, no espaçamento de 5,0 m x 5,0 m. Sendo: $\mathrm{T}_{1}$ $=$ testemunha (sem adubação); $\mathrm{T}_{2}=$ adubação química $(\mathrm{NPK}) ; \mathrm{T}_{3}=$ esterco de bovino; $\mathrm{T}_{4}=$ esterco de aves; $\mathrm{T}_{5}=\mathrm{NPK}+$ esterco de caprino, $\mathrm{T}_{6}=$ esterco de aves $+3 \mathrm{~kg}$ de pó de rocha e $\mathrm{T}_{7}=$ esterco de caprino. As gravioleiras no início da pesquisa estavam com 42 meses de idade e o experimento conduzido entre os meses de janeiro a setembro de 2014. 
A adubação mineral foi realizada de acordo com a análise química do solo, levando em consideração os macronutrientes ( $\mathrm{P}$ e K). Quanto ao nitrogênio, a recomendação foi de acordo com Cavalcanti (2008), para a cultura da gravioleira em produção. Os atributos químicos do solo, na camada 0-20 cm de profundidade, apresentou os seguintes valores: $\mathrm{pH}=$ 4,9; $\mathrm{P}=3,67 \mathrm{mg} \mathrm{dm}^{-3} ; \mathrm{K}^{+}=39,00 \mathrm{mg} \mathrm{dm}^{-3} ; \mathrm{Na}^{+}=0,07 \mathrm{cmol}_{\mathrm{c}} \mathrm{dm}^{-3} ; \mathrm{H}^{+}+\mathrm{Al}^{3+}=8,0 \mathrm{cmol}_{\mathrm{c}} \mathrm{dm}^{-}$ 3; $\mathrm{Al}^{3+}=0,85 \mathrm{cmol}_{\mathrm{c}} \mathrm{dm}^{-3} ; \mathrm{Ca}^{2+}=1,5 \mathrm{cmol}_{\mathrm{c}} \mathrm{dm}^{-3} ; \mathrm{Mg}^{2+}=1,35 \mathrm{cmol}_{\mathrm{c}} \mathrm{dm}^{-3}$; soma de bases de $3,02 \mathrm{cmol}_{\mathrm{c}} \mathrm{dm}^{-3} ; \mathrm{CTC}=11,02 \mathrm{cmol}_{\mathrm{c}} \mathrm{dm}^{-3} ; \mathrm{V}=27,40 \% ; \mathrm{m}=21,96 \%$ e matéria orgânica de $34,03 \mathrm{~g} \mathrm{~kg}^{-1}$.

A adubação orgânica foi realizada de acordo com análise química dos estercos, levando-se em consideração apenas o teor de fósforo. Os teores de nutrientes dos estercos foram os seguintes: aves: 7,9 $\mathrm{g} \mathrm{kg}^{-1}$ de $\mathrm{N} ; 15,8 \mathrm{~g} \mathrm{~kg}^{-1}$ de P e 8,4 $\mathrm{g} \mathrm{kg}^{-1}$ de K. Caprino: $12,8 \mathrm{~g}$ $\mathrm{kg}^{-1}$ de $\mathrm{N} ; 15,2 \mathrm{~g} \mathrm{~kg}^{-1}$ de P e 23,5 $\mathrm{g} \mathrm{kg}^{-1}$ de K. Bovino: 7,4 $\mathrm{g} \mathrm{kg}^{-1}$ de $\mathrm{N} ; 1,5 \mathrm{~g} \mathrm{~kg}^{-1}$ de P e 4,6 $\mathrm{g}$ $\mathrm{kg}^{-1}$ de $\mathrm{K}$.

A calagem do solo foi realizada de acordo com a análise química do solo, aplicando-se calcário dolomítico $\left(\mathrm{CaO}\right.$ de 32,3\%; $\mathrm{MgO}$ de $19,3 \% ; \mathrm{SiO}_{2}$ de $\left.0,86 \%\right)$ e gesso agrícola $(\mathrm{CaO}$ de $17,1 \% ; \mathrm{MgO}$ de $1,1 \% ; \mathrm{SiO}_{2}$ de 18,0$)$ na projeção da copa, sendo realizada em todos os tratamentos, inclusive na testemunha.

As variáveis analisadas para os teores foliares foram: concentração interna de $\mathrm{CO}_{2}$ na câmara subestomática $\left(\mathrm{Ci}-\mu \mathrm{mol} \mathrm{mol}^{-1}\right)$, a condutância estomática de vapores de água ( $g s-$ mol m $\left.\mathrm{m}^{-1} \mathrm{~s}^{-1}\right)$, a taxa de transpiração $\left(E-\mathrm{mol} \mathrm{H}_{2} \mathrm{O} \mathrm{m}^{-2} \mathrm{~s}^{-1}\right)$, a taxa fotossintética $\left(A-\mu \mathrm{mol} \mathrm{m} \mathrm{m}^{-2}\right.$ $\left.\mathrm{s}^{-1}\right)$, eficiência de carboxilação $\left(A / C i-\mu \mathrm{mol} \cdot \mathrm{m}^{-2} \cdot \mathrm{s}^{-1}\right)$, e eficiência do uso da água $(A / E-\mu \mathrm{mol}$ $\mathrm{CO}_{2}\left(\mathrm{mmol} \mathrm{H} \mathrm{H}_{2} \mathrm{O}\right)^{-1}$.

As avaliações das trocas gasosas foram feitas em campo, após 60 dias da última adubação nitrogenada, no intervalo das 8:00 às 11:00 horas. As leituras foram realizadas no terceiro par de folha, partindo do ápice dos ramos, sendo aferidas as leituras em duas extremidades da planta de gravioleira, com o auxílio de um sistema portátil de análise de gases a infravermelho (IRGA LCA4 - ADC Instruments).

Os dados obtidos foram submetidos à análise de variância, utilizando-se até $5 \%$ de significância para o teste $\mathrm{F}$. As médias foram comparadas pelo teste de Tukey a 5\% de probabilidade. Utilizou-se o software SAS ${ }^{\circledR} 9.3$ (SAS, 2011) para as análises. 


\section{Resultados e Discussão}

Conforme indicado na Tabela 1, observa-se efeito significativo dos tratamentos, sobre a taxa fotossintética e a eficiência de carboxilação a $5 \%$ de probabilidade pelo teste $\mathrm{F}$.

\begin{tabular}{|c|c|c|c|c|c|}
\hline Fonte de variação & GL & $\mathrm{Ci}$ & $E$ & $g s$ & $A$ \\
\hline Blocos & 3 & 1595,9166 & 0,7568 & 0,0031 & 1,5285 \\
\hline Tratamentos & 6 & $1366,7648 \mathrm{~ns}$ & $0,4665 \mathrm{~ns}$ & $0,0019 \mathrm{~ns}$ & $6,2787 *$ \\
\hline Resíduo & 18 & 2079,3958 & 0,5499 & 0,0018 & 3,5326 \\
\hline Total & 27 & 50417,4642 & 14,9687 & 0,0541 & 105,8461 \\
\hline $\mathrm{CV}(\%)$ & - & 15,5 & 46,7 & 55,9 & 57,6 \\
\hline
\end{tabular}

\begin{tabular}{cccc}
\hline Fonte de variação & GL & $\boldsymbol{A} / \boldsymbol{C} \boldsymbol{i}$ & $\boldsymbol{A} / \boldsymbol{E}$ \\
\hline Blocos & 3 & 0,00000516 & 1,3072 \\
Tratamentos & 6 & $0,00009232 *$ & $0,7474 \mathrm{~ns}$ \\
Resíduo & 18 & 0,00005057 & 1,0930 \\
Total & 27 & 0,00147975 & 28,0810 \\
\hline CV (\%) & - & 60,7 & 49,3 \\
\hline & *: significativo a 5 \%; ns: não significativo, pelo teste F.
\end{tabular}

As médias da concentração interna de $\mathrm{CO}_{2}(\mathrm{Ci})$, variaram de 321,63 a $274,13 \mu \mathrm{mol}$ $\left.\mathrm{mol}^{-1}\right)\left(\mathrm{T}_{7}\right)\left(\mathrm{T}_{3}\right)$ (Figura 1). Esses valores estão acima dos verificados por Baron (2010), que trabalhando com araticum-de-terra-fria (Annona emarginata L.), cultivadas em solução nutritiva obteve médias que variaram de 174 a $249 \mu \mathrm{mol} \mathrm{mol}^{-1}$.

De acordo com Silva et al. (2010) a manutenção da concentração interna de $\mathrm{CO}_{2}$ associada com a baixa taxa de assimilação de $\mathrm{CO}_{2}$, pode ocasionar um aumento na susceptibilidade a danos fotoquímicos, pois reduções na assimilação de $\mathrm{CO}_{2}$ causam excesso 
de energia luminosa no fotossistema II, constituindo uma resposta indireta do fechamento estomático.

Figura 1. Concentração interna de $\mathrm{CO}_{2}$ na câmara subestomática, da gravioleira, sob influência da adubação orgânica e mineral.

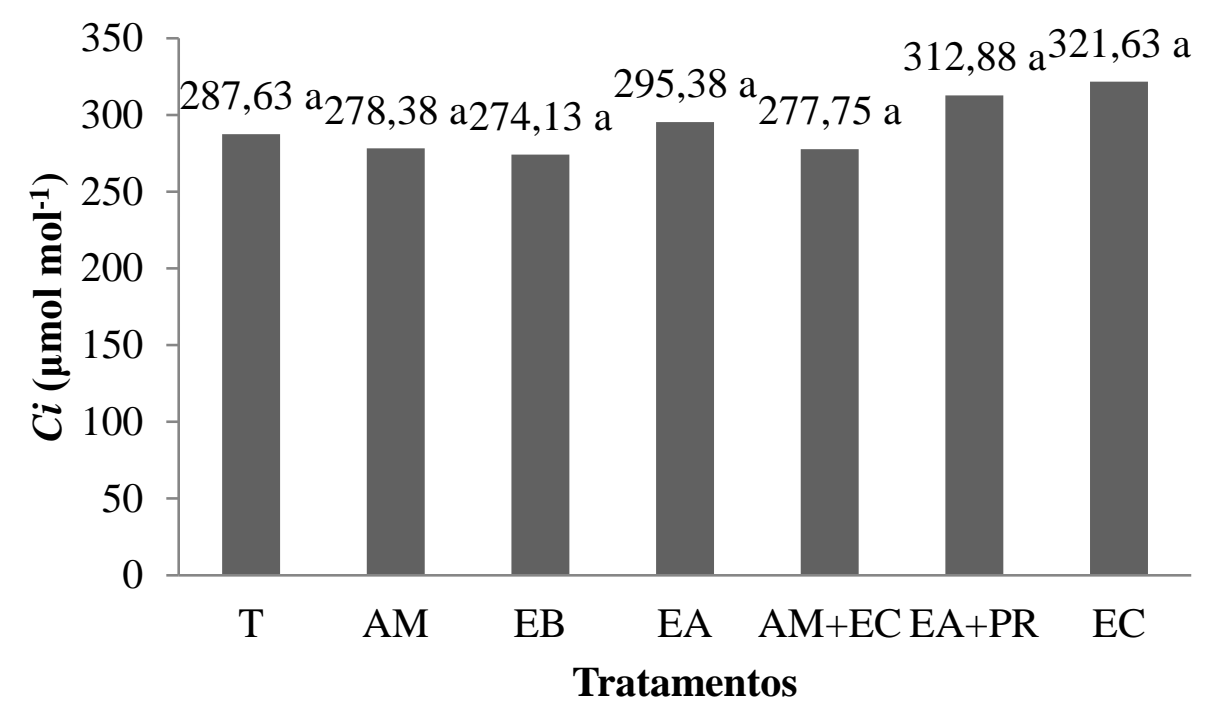

Médias seguidas pela mesma letra não diferem entre si pelo teste de Tukey a 5\% de probabilidade.

$\mathrm{T}=$ testemunha; $\mathrm{AM}=$ adubação mineral $; \mathrm{EB}=$ esterco bovino; $\mathrm{EA}=$ esterco de aves; $\mathrm{AM}+\mathrm{EC}=$ adubação mineral mais esterco caprino; $\mathrm{EA}+\mathrm{PR}=$ esterco de aves mais pó de rocha; $\mathrm{EC}=$ esterco caprino.

Com relação à taxa de transpiração $(E)$, as médias variaram de 2,11 a 1,09 $\mathrm{mol} \mathrm{H}_{2} \mathrm{O} \mathrm{m}^{-}$ ${ }^{2} \mathrm{~s}^{-1}\left(\mathrm{~T}_{2}\right)\left(\mathrm{T}_{7}\right)$ (Figura 2). Braga (2010) e Rocha (2013) trabalharam com biofertilizante, constataram que sua aplicação não proporcionou efeito significativo sobre a taxa transpiratória do pinhão manso. Mantoan (2013) avaliando as trocas gasosas em plantas de araticum-de-terra-fria (Annona emarginata L.) submetidas ao estresse hídrico obteve médias que variaram de 0,59 a $0,89 \mathrm{~mol} \mathrm{H}_{2} \mathrm{O} \mathrm{m} 2 \mathrm{~s}^{-1}$, sendo abaixo dos observados na presente pesquisa.

De acordo com Klar (1988) a transpiração é um fator importante que interfere na produtividade das plantas, pois esta auxilia na translocação de compostos dentro da célula, além de ser um importante fator no resfriamento dos tecidos. 
Figura 2. Taxa de transpiração, da gravioleira, sob influência da adubação orgânica e mineral.

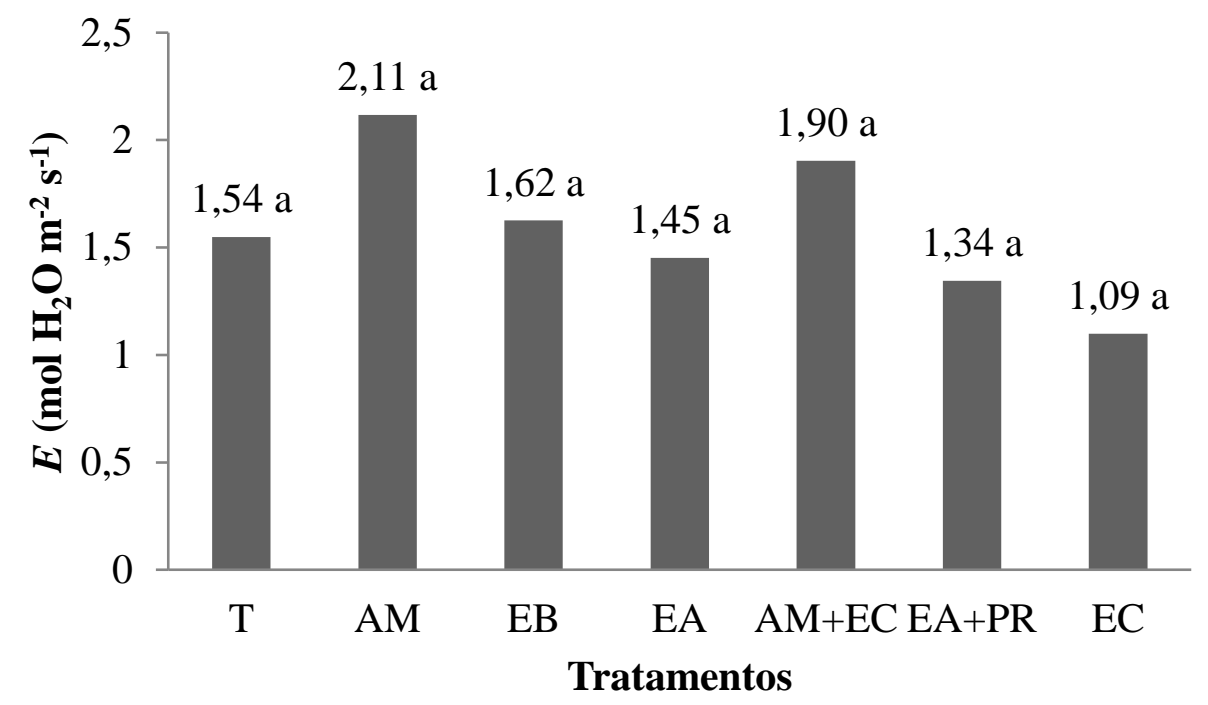

Médias seguidas pela mesma letra não diferem entre si pelo teste de Tukey a 5\% de probabilidade.

$\mathrm{T}=$ testemunha; $\mathrm{AM}=$ adubação mineral $\mathrm{EB}=$ esterco bovino; $\mathrm{EA}=$ esterco de aves; $\mathrm{AM}+\mathrm{EC}=$ adubação mineral mais esterco caprino; $\mathrm{EA}+\mathrm{PR}=$ esterco de aves mais pó de rocha; $\mathrm{EC}=$ esterco caprino.

A respeito da condutância estomática $(g s)$, as médias variaram de 0,11 a $0,05 \mathrm{~mol} \mathrm{~m}^{-1}$ $\mathrm{s}^{-1}\left(\mathrm{~T}_{2}\right)\left(\mathrm{T}_{7}\right)$. Mantoan (2013) avaliando as trocas gasosas em plantas de araticum-de-terra-fria submetidas ao estresse hídrico, obteve médias que variaram de 0,014 a $0,036 \mathrm{~mol} \mathrm{~m}^{-1} \mathrm{~s}^{-1}$, sendo abaixo dos obtidos nessa pesquisa. De acordo com Silva et al. (2004) em situação de baixa disponibilidade de água no solo as plantas reduzem a perda de água ao reduzir a condutância estomática. É um dos mecanismos que demonstram o controle estomático em plantas submetidas ao déficit hídrico. 
Figura 3. Condutância estomática de vapores de água da gravioleira, sob influência da adubação orgânica e mineral.

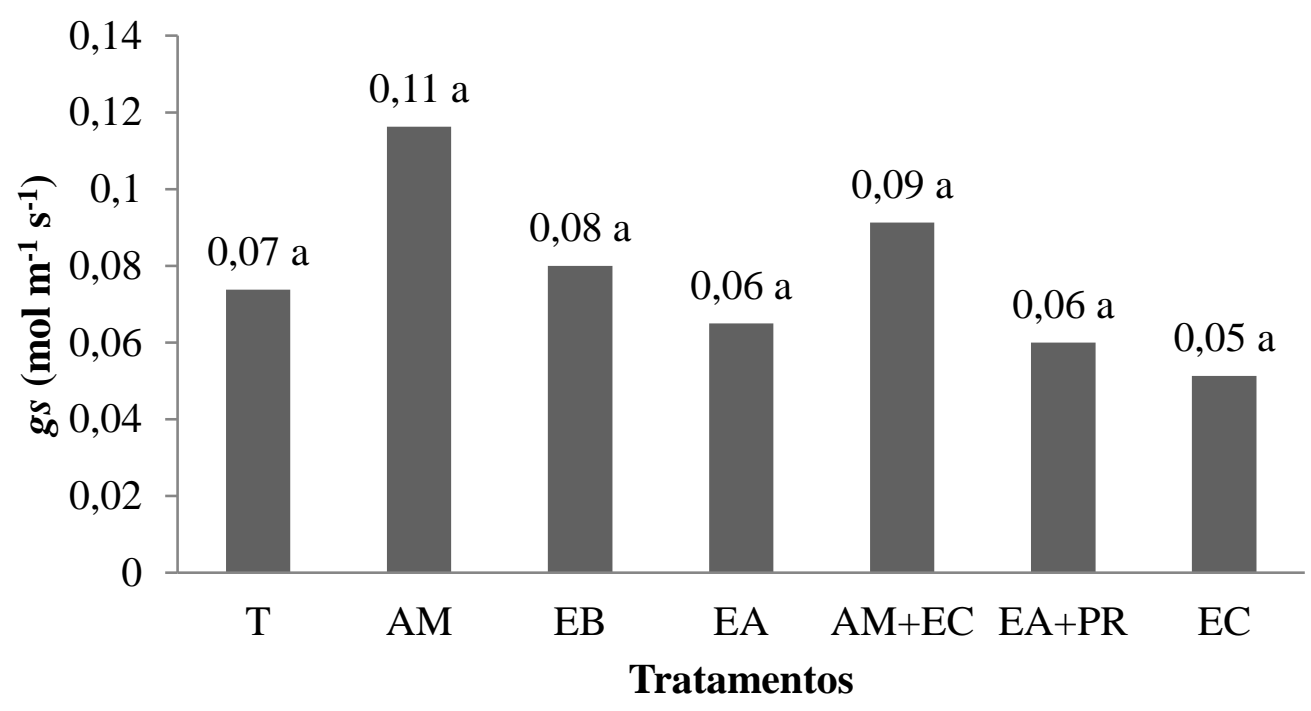

Médias seguidas pela mesma letra não diferem entre si pelo teste de Tukey a 5\% de probabilidade.

$\mathrm{T}=$ testemunha; $\mathrm{AM}=$ adubação mineral $; \mathrm{EB}=$ esterco bovino; $\mathrm{EA}=$ esterco de aves; $\mathrm{AM}+\mathrm{EC}=$ adubação mineral mais esterco caprino; $\mathrm{EA}+\mathrm{PR}=$ esterco de aves mais pó de rocha; $\mathrm{EC}=$ esterco caprino.

Na figura 4, observa-se que a maior taxa fotossintética $(A)$ foi obtida quando as plantas foram submetidas à adubação mineral $\left(1,7 \mu \mathrm{mol} \mathrm{m} \mathrm{m}^{-2} \mathrm{~s}^{-1}\right)\left(\mathrm{T}_{2}\right)$. A menor média para essa variável foi constatada no tratamento com esterco caprino $\left(0,49 \mu \mathrm{mol} \mathrm{m} \mathrm{m}^{-2} \mathrm{~s}^{-1}\right)$. O aumento da taxa fotossintética provavelmente esteja relacionada com o aumento da abertura estomática, o que permite maior difusão de $\mathrm{CO}_{2}$ para os espaços intercelulares, contribuindo para elevação das taxas de fotossíntese. Baron (2010) trabalhando com araticum-de-terra-fria cultivadas em solução nutritiva obteve médias que variaram de 5,34 a $12,3 \mu \mathrm{mol} \mathrm{m} \mathrm{m}^{-2} \mathrm{~s}^{-1}$, sendo acima dos verificados nesse trabalho. 
Figura 4. Taxa fotossintética da gravioleira, sob influência da adubação orgânica e mineral.

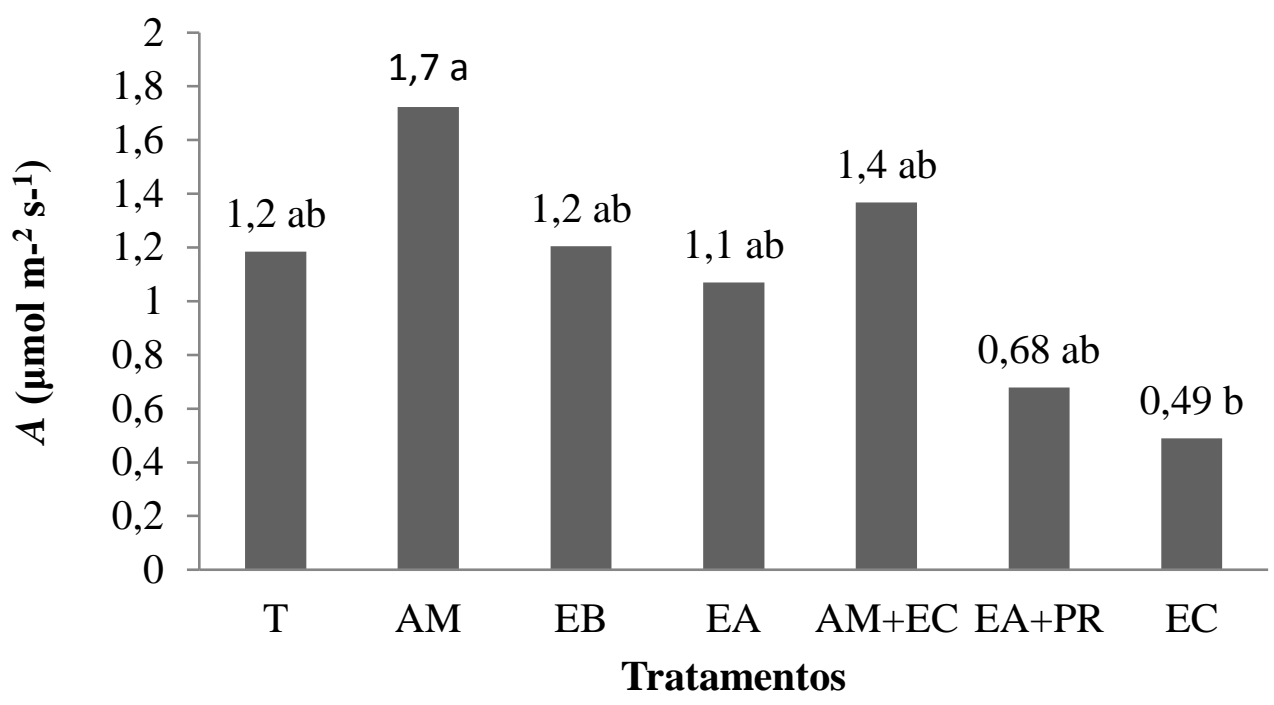

Médias seguidas pela mesma letra não diferem entre si pelo teste de Tukey a 5\% de probabilidade.

$\mathrm{T}=$ testemunha; $\mathrm{AM}=$ adubação mineral $\mathrm{EB}=$ esterco bovino; $\mathrm{EA}=$ esterco de aves; $\mathrm{AM}+\mathrm{EC}=$ adubação mineral mais esterco caprino; $\mathrm{EA}+\mathrm{PR}=$ esterco de aves mais pó de rocha; $\mathrm{EC}=$ esterco caprino.

Com relação à eficiência de carboxilação $(A / C i)$, os tratamentos exerceram efeito significativo pelo teste de Tukey a $5 \%$ de probabilidade. Sendo, a maior média $(0,019$ $\mu$ mol. $\left.\mathrm{m}^{-2} \cdot \mathrm{s}^{-1}\right)$ obtida quando as plantas foram adubadas com adubação mineral constituída por NPK (Figura 5). De acordo com Larcher (2006) e Anjos et al. (2014) a eficiência de carboxilação é definida como a velocidade com que o $\mathrm{CO}_{2}$ fixado é processado. Anjos et al. (2014) firmam que a velocidade de fixação depende, principalmente, da quantidade e atividade enzimática e pela disponibilidade de $\mathrm{CO}_{2}$, pela temperatura, do suprimento de substâncias minerais, do grau de desenvolvimento e atividade da planta. Baron, (2010) avaliando as trocas gasosas e índices fisiológicos de Anonna emarginata L. registrou valores acima $\left(0,053 \mu \mathrm{mol} \cdot \mathrm{m}^{-2} \cdot \mathrm{s}^{-1}\right)$ dos observados nesse estudo. 
Figura 5. Eficiência de carboxilação da gravioleira, sob influência da adubação orgânica e mineral.

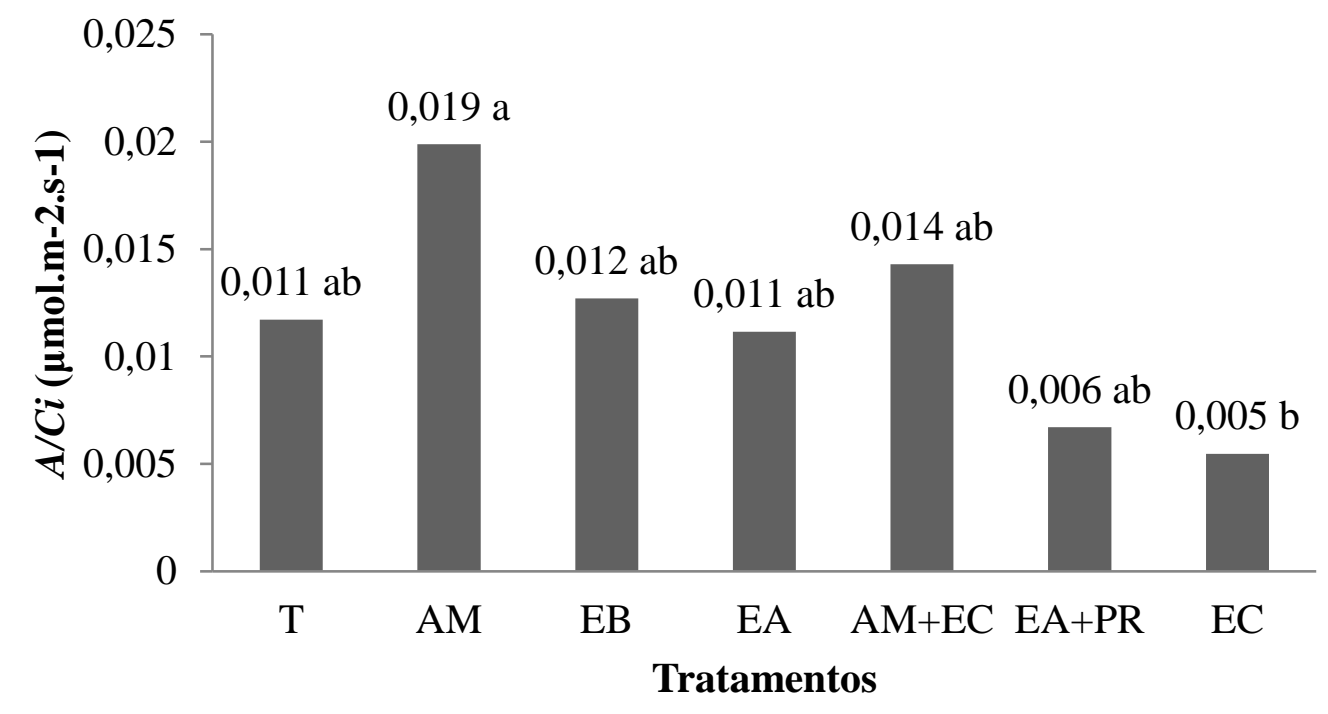

Médias seguidas pela mesma letra não diferem entre si pelo teste de Tukey a 5\% de probabilidade.

$\mathrm{T}=$ testemunha; $\mathrm{AM}=$ adubação mineral $\mathrm{EB}=$ esterco bovino; $\mathrm{EA}=$ esterco de aves; $\mathrm{AM}+\mathrm{EC}=$ adubação mineral mais esterco caprino; $\mathrm{EA}+\mathrm{PR}=$ esterco de aves mais pó de rocha; $\mathrm{EC}=$ esterco caprino.

Não observou efeito dos tratamentos para à eficiência do uso da água $(A / E)$ pelo teste de Tukey a $5 \%$ de probabilidade. As médias variaram de 1,5 a 2,6 em $\mu$ mol $\mathrm{CO}_{2} \mathrm{mmol} \mathrm{H}_{2} \mathrm{O}^{-1}$ $\left(\mathrm{T}_{2}\right)\left(\mathrm{T}_{7}\right)$ respectivamente (Figura 6). Esses resultados denotam a inexistência de estresse hídrico sofrido pela gravioleira durante a condução do experimento. 
Figura 6. Eficiência do uso da água da gravioleira, sob influência da adubação orgânica e mineral.

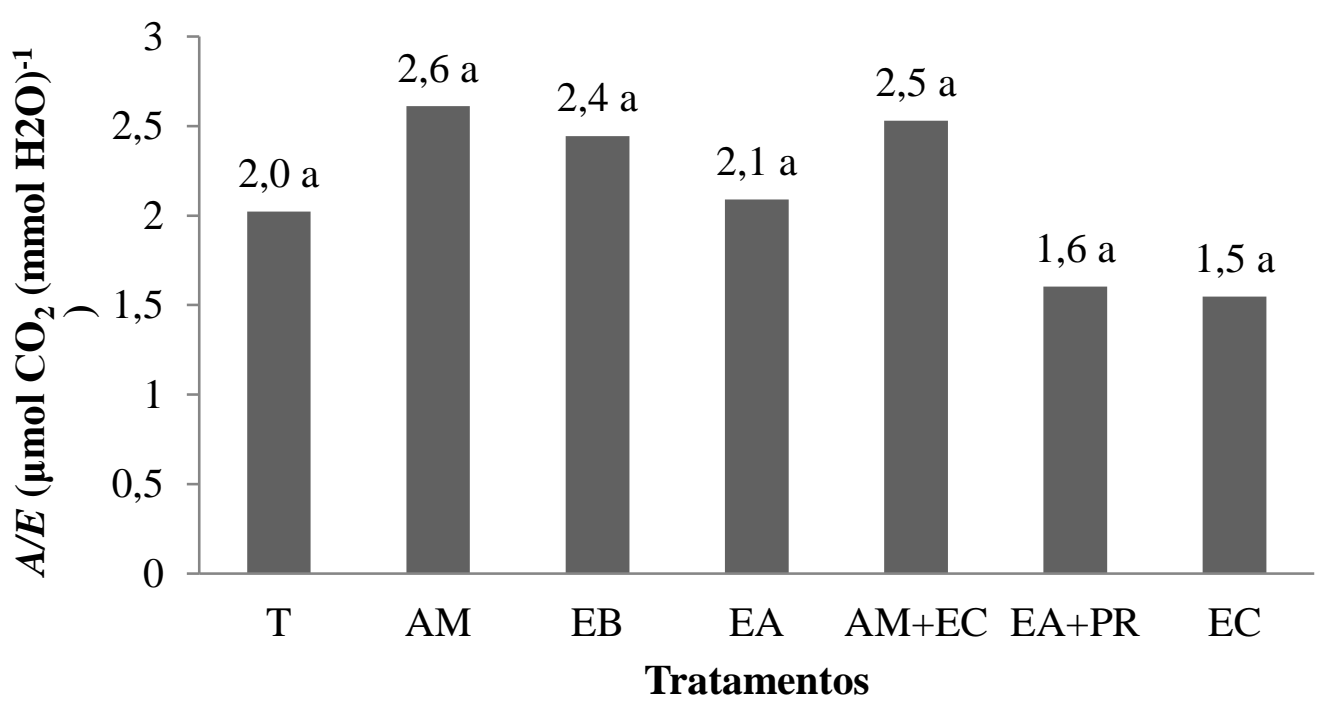

Médias seguidas pela mesma letra não diferem entre si pelo teste de Tukey a 5\% de probabilidade.

$\mathrm{T}=$ testemunha; $\mathrm{AM}=$ adubação mineral $\mathrm{EB}=$ esterco bovino; $\mathrm{EA}=$ esterco de aves; $\mathrm{AM}+\mathrm{EC}=$ adubação mineral mais esterco caprino; $\mathrm{EA}+\mathrm{PR}=$ esterco de aves mais pó de rocha; $\mathrm{EC}=$ esterco caprino.

\section{Considerações finais}

A adubação mineral com NPK proporcionou maior taxa fotossintética e eficiência de carboxilação na gravioleira 'Morada'.

A concentração interna de $\mathrm{CO}_{2}$, condutância estomática, taxa de transpiração e eficiência de uso da água não foram afetadas pelos tratamentos.

\section{Referências}

ALMEIDA, L. P. Germinação, crescimento inicial e anatomia foliar de plantas jovens de Cryptocarya aschersoniana Mez. sob diferentes níveis de radiação. 2001. 96f Dissertação (Mestrado em Fisiologia Vegetal) Universidade Federal de Lavras, Lavras, 2001.

ANJOS, D. N.; VASCONCELOS, R. C. V.; MENDES, H. T. A.; ANNE CAROLINE VIEIRA CANGUSSU, A. C. V. Trocas gasosas em plantas de feijoeiro submetidas à fitorreguladores, NPK e micronutrientes. Enciclopédia Biosfera, Centro Científico Conhecer - Goiânia, v.10, n.19; p. 1796, 2014.

BARON, D. Desenvolvimento de plantas jovens de Annona emarginata (Schltdl) H. Rainer. (Araticum-de-terra-fria) cultivadas em solução nutritiva. 2010. 103f Dissertação (Mestrado - Instituto de Biociências), Universidade Estadual Paulista. Botucatu, 2010. 
BRAGA, E. S. Crescimento inicial e aspectos fisiológicos do pinhão manso fertirrigado com biofertilizante bovino. 2010. 43f. Monografia (Curso de graduação em agronomia), Universidade Federal do Ceará, Fortaleza, 2010.

BRASIL, Ministério da Agricultura. Levantamento exploratório-reconhecimento de solos do estado da Paraíba. Rio de Janeiro: MA/SUDENE, 669 p. (Boletim Técnico, 15). 1972.

CAVALCANTI, F. J. A. (Coord.). Recomendações de adubação para o estado do Pernambuco ( $2^{\mathbf{a}}$ aproximação). 3. ed. Recife: Instituto Agronômico do Pernambuco-IPA, 2008. 212 p.

CIOMPI, S.; GENTILE, E.; GUIDI, L.; SOLDATINI, G.F. The effect of nitrogen deficiency on leaf gas exchange and chlorophyll fluorescence parameters in sunflower. Plant Science. 118: 177-184, 1996.

GONDIM, A. W. A.: Geoeconomia e Agricultura do Brejo Paraibano: análise e avaliação. João Pessoa: Imprensa Universitária, 82p. 1999.

KLAR, A.E. Evapotranspiração. In: A água no sistema solo-planta-atmosfera. $2^{a}$ ed. São Paulo: Nobel, 1988.

LIMA, J. S. Crescimento, eficiência quântica potencial do fotossistema II e composição mineral da gravioleira 'Morada' sob adubação nitrogenada. 2012. Dissertação (Mestrado em Agronomia), Centro de Ciências Agrárias, Universidade Federal da Paraíba, Areia, 2012.

LOPES, M. N.; CÂNDIDO, M. J. D.; POMPEU, R. C. F. F. et al. Biomass components in Massai grass during establishment and regrowth under five nitrogen fertilization levels. Revista Brasileira de Zootecnia, v. 40, n. 8, p. 1629-1637, 2011.

MANTOAN, L.P.B. Recuperação das trocas gasosas e fluorescência da clorofila a em plantas de Annona emarginata (schltdl.) h. rainer submetidas a estresse hídrico. 2013. 117f. Dissertação (mestrado) - Instituto de Biociências, Universidade Estadual Paulista, Botucatu.

MARÇAL, J. A. Crescimento inicial do pinhão-manso (Jatropha curcas L.) sob irrigação com águas salinas em solo com matéria orgânica. 2011. 80 f. (Dissertação de Mestrado), Centro de Ciências Agrárias, Universidade Federal da Paraíba. Areia, 2011.

MELO JUNIOR. A. P.; ALVES. A. S.; SILVA. P.F.; LIMA JUNIOR. B. C.; FARIAS. M. S. S. Eficiência das trocas gasosas em bananeira sob diferentes fontes e níveis de nitrogênio e potássio. II Inovagri International Meeting. Fortaleza-Brasil-2014.

POMPEU, R. C. F. F.; CÂNDIDO, M. J. D.; LOPES, M. N. et al. Características morfofisiológicas do capim-aruana sob diferentes doses de nitrogênio. Revista Brasileira de Saúde e Produção Animal, v. 11, n. 4, p. 1187-1210, 2010.

QIU, J., ISRAEL, D.W. Carbohydrate accumulation and utilization in soybean plants in response to altered phosphorus nutrition. Plant Physiology. v. 90, p. 722-728, 1994. 
RAO, I.M., TERRY, N. Leaf phosphate status, photosynthesis, and carbon partitioning in sugar beet IV. Changes with time following increased supply of phosphate to low-phosphate plants. Plant Physiology. v. 107, p. 1313-1321, 1995.

ROCHA, M. G. Adubação orgânica e nitrogenada em videira cv. Syrah no vale do submédio São Francisco. 2013. Tese (Irrigação e Drenagem) Faculdade de Ciências Agronômicas, Universidade Estadual Paulista. Botucatu, 2013.

SANTOS, M. G.; RIBEIRO, R. V.; OLIVEIRA, R. F.; MACHADO, E. C.; PIMENTEL, C. The role of inorganic phosphate on photosynthesis recovery of common bean after a mild water deficit. Plant Science, v. 170, p. 659-664, 2006.

SILVA O. S., SANTOS-SEREJO J. A., CORDEIRO, Z. J. M. In: BORGES A. L.; SOUZA, L. S. O cultivo da bananeira. Variedades. 21. ed. Cruz das Almas: Embrapa, 2004. p. 45-58.

SILVA, E. N.; RIBEIRO, R. V.; FERREIRA-SILVA, S. L.; VIÉGAS, R. A.; SILVEIRA, J. A. G. Comparative effects of salinity and water stress on photosynthesis, water relations and growth of Jatropha plants. Journal of Arid Environments, v.74, p.1130-1137, 2010.

SHIMAZAKI, K.I. Light regulation of stomatal movement. Annual Review of Plant Biology, Palo Alto,v.58, p.219-247. 2007.

SHUBHRA; DAYAL, J.; GOSWAMI, C. L.; MUNJAL, R. Influence of phosphorus application on water relations, biochemical parameters and gum content in cluster bean under water deficit. Biologia Plantarum, v. 48(3), p. 445-448, 2004.

STATISTICAL ANALYSIS SYSTEM INSTITUTE, SAS - Institute SAS/STAT software 2011, CD-ROOM.

VIANA, T. V. A.; SANTOS. A. P. G.; SOUSA, G. G.; PINHEIRO NETO, L. G.; BENITO M. DE AZEVEDO, B. M.; AQUINO, B. F. Trocas gasosas e teores foliares de npk em meloeiro adubado com biofertilizantes. Agrária - Revista Brasileira de Ciências Agrárias. 1981-0997 v.8, n.4, p.595-601, 2013. 